\section{Global nomads in the digital veldi*}

\begin{abstract}
I would like to explore the implications of mobile com-munication by contextualizing it both historically and in terms of the use of other types of media. This requires analysis on a high level of abstraction. Rather than engaging in a micro-level analysis of the everyday use of mobile phones, I will attempt to present a macro-level argument about the place of mobile telephony in the overall evolution over the millennia of forms of human connections to places and connections among people. My general argument is that as we are moving swiftly into a new era of globalization and wireless communication, we are also spiraling backward, in some key ways, to the earliest form of human association: nomadic hunting and gathering. We are, in short, becoming "global nomads."
\end{abstract}

\section{RESUMO}

O texto explora as implicações da comunicação móvel em termos de contextualização histórica e no uso de distintas mídias.

\section{KEY WORDS (PALAVRAS-CHAVE)}

- Mobile Communication (Comunicação Movel)

- Medias (Mídias)

- Globalization (Globalização)

Joshua Meyrowitz

University of New Hampshire/USA

\section{Hunting and gathering together}

THOSE ANCIENT NOMADIC societies that have survived into current times give us a window into the nature of our deep past. ${ }^{1}$ When the earliest humans hunted and gathered for survival, they relied on-and could rarely escape from - the close physical proximity of others in their group. Although there was some separation of labor by sex $^{2}$, men and women could not get away from each other consistently enough to develop highly distinct roles for each gender. With no separate "workplace" and no fixed "home," both men and women were involved in childcare; both men and women participated in the group's political decision-making.

Modern conceptions of "childhood" could also not exist in nomadic societies. Without walls, doors, rooms, or neighborhoods, children could not be separated easily from the activities of adults. Children were not shielded from a set of "adult secrets" about such things as sex and death. Children's play mirrored the full range of adult activities and gradually evolved into adult participation in the group. Children were not particularly in awe of, or highly respectful toward, adults.

Without distinct social spheres, nomadic leadership was also not a distant and mystified phenomenon. Because would-be leaders could not escape the scrutiny of those to be led, leaders had to work the hardest, while simultaneously exposing themselves to constant challenges, criticism, even ridicule.

In nomadic societies, different types of social activities also overlapped. Whatever strains of activity we might now recognize as education, business, politics, healthcare, housework, news, socializing, and entertainment in this form of social organization 
were intertwined components of the totality of everyday life.

\section{Settling and separating}

Until very recently, most of the subsequent developments in human civilization following the nomadic period have involved the creation of more separations between different types of people and activities and entailed the development of thicker boundaries. Or, stated in another way, the growing separations and the thickening of boundaries were the means by which "differences" among people and among activities were marked and highlighted. As attachments to fixed places developed with more reliance on agriculture and tribal forms of organization, for example, the once shared social space began to splinter. In place-specific tribal societies, a rudimentary public sphere developed with special "men's places" (a particular hut, for example), and women were increasingly relegated to a domestic sphere.

In place-defined oral societies, children's activities were separated from adult activities, but only by a single "rite of passage." This transition from childhood to adulthood was generally correlated with puberty, though not very rigorously. The real passage was not a biological one, but an informational and experiential one. The about-to-be adults were separated from the remaining children, exposed to new places, told the secrets of adult life in the tribe, incorporated into new activities, and dressed in new clothes.

Attachments to places also permitted the development of holy places, where priests and headmen could maintain their status through distance and mystery. That is, they could restrict access to themselves, use secret items and substances, and engage in secret practices. They could, in short, keep their public role performances distinct from private rehearsal and relaxation places.
Yet, for these early settled peoples, the continued reliance on oral forms of communication - relatively equally accessible to all those who could speak and hear-made it difficult to create many distinct spheres of culture.

\section{Literate segregations}

The divisions in roles and activities that developed in settled societies grew geometrically with the spread of literacy, particularly after the invention of printing, one of the earliest forms of mass production and mass distribution. Reading and writing are not as natural as hearing and speaking, and they are not as easily learned. With some variation in different cultures (based in part on differences in writing systems, such as phonetic vs. pictographic), literate classes became distinct from illiterate classes. Literacy further encouraged the splintering of identities based on levels of reading ability and sets and subsets of literatures.

In Western cultures, children were increasingly separated from adults, and children of different ages (and reading abilities) were increasingly isolated from each other. Eventually, childhood splintered into yearby-year steps of socialization characterized by distinct roles, information sets, and experiences. Each age group had its own literature. (To this day, many children's books in the United States have a small number code on the back cover, such as "3:2," which means "third grade, second month.")

Men's and women's information access and activities were also increasingly segregated. At the height of Western print culture, the Victorians explicitly spoke of the "two spheres": The public male realm of rational accomplishments and brutal competitions, and the private, female sphere of home, childrearing, intuition, and emotion. Men and women were not supposed to know very much about the "other's" sphere, and were certainly not encouraged to participate fully in it. 
Leadership, too, grew more distinct in literate cultures. As early as Machiavelli's $16^{\text {th }}$ century volume, The Prince, political advisors were guiding leaders to take advantage of the new potential inaccessibility and invisibility of print-era leadership by revealing only selected aspects of themselves to the public. Multiple hierarchies developed, with many steps in each.

As part of the same segregating process, social activities became increasingly differentiated: work, leisure, education, trade, healing, and on and on-all in their separate places. Each distinct setting developed its own set of rules and roles.

\section{Electronic blurrings}

This very broad sketch of social evolution obviously omits an enormous amount of detail about human life, including significant changes in the scale and complexity of societies over time, key variations in social forms across cultures, and other differences within cultures, such as variations across regions and between different social classes. Yet, the broad, schematic nature of this outline of the increasing segregation of experiential spheres also makes it easier to see the oddity of the next step in human social evolution - the electronic era, with its sub-developments of digital and wireless communications.

On the surface, the development and spread of a new form of technically complex electronic equipment and media of communication-beginning slowly in the mid-19 ${ }^{\text {th }}$ century with the demonstration of the telegraph and escalating beyond all prior imaginings by the late $20^{\text {th }}$ century - would seem to move the historical segregation process yet another step forward. Surely, we have a great gap between informationrich and information-poor cultures, as well as vast differences in control over physical resources. Many other divisions remain in perspective, expertise, and opportunity. Yet, when we look at the basic social struc- ture of early $21^{\text {st }}$-century America and of other electronic cultures, we can see some striking echoes of hunter and gatherer societies.

Of course, we don't roam our whole lives with the same small band of extended family. Our interactions are more individualized, more idiosyncratic, more variable, more customized. There are also complex political, economic, and military organizations that shape and limit the patterns of access to resources to be hunted and gathered. On a basic behavioral level, however, we have returned in many ways to the overlapping experiences and role blurrings of nomads. Once again, we have a hard time getting away from each other. That is, it is increasingly difficult to separate one social sphere from another, one activity from another, one set of knowledge and experience from another.

With the ubiquity of televisions, computers, and other electronic media, we find it increasingly difficult to segregate children from what society once considered exclusively "adult" topics and secrets and technologies. Our children's worlds are filled with images of violence, sex, and death, as well as with images and sounds of the banalities of everyday adult life. And the old, yearby-year, staggered access to informationwhere children of each age and reading level were exposed to entirely different sets of information - is largely bypassed.

Similarly, men and women's roles are increasingly overlapping. Working and careers have become more important in women's lives, and parenting and family have become more important in men's lives.

In the same way, many traditional hierarchies are flattening, at least behaviorally. We watch our leaders too closely for them to seem very special. And seemingly endless journalistic analyses, talk-show jokes, public gossip, and web-site postings are devoted to leaders' political failures, personality flaws, annoying facial expressions, misuse of language, and sexual im- 
proprieties. (These changes in perception of leaders' personal authority, however, are not necessarily accompanied by a comparable decline in their political power to shape domestic policy or wage war.)

The spatial and temporal differences between different types of social activities are also fading. With computers, mobile phones, and the Internet, many different tasks - such as shopping, paying the bills, doing homework, exploring a medical problem, communicating with friends, making a business proposal, planning a protest demonstration, trying to meet interesting strangers - take place in no particular place, and involve the same basic position and movements of body, head, and hands. Moreover, two or more of these activities can be engaged in simultaneously.

\section{Fluid definitions of situations}

With a greater proportion of our interactions taking place via electronic media, physical co-presence is diminishing as a determinant of the nature of interactions. "What's going on here?" is no longer as easily answered as it once was by assessing who is in (and not in) a particular place, for how long, and for what purpose. A "definition of the situation" no longer "saturates" a time/space frame in the way that sociologist Erving Goffman described. ${ }^{3}$ A seemingly clear definition of an interaction can instantly be altered by the ring of even one participant's mobile phone or by a news bulletin on a radio or TV station that pulls everyone's thoughts in a new direction. Definitions of situations are now highly fluid and changeable. Moreover, the situations that emerge via electronic blendings may not match any prior definitions. For example, when an executive at a business meeting takes a mobile phone call from an intimate, she is likely to violate two sets of rules at the same instant: Her style of speaking may be too personal for a business meeting and simultaneously too cold for a conversation with a close friend or lover. The same violations of two prior sets of social rules occur with mobile phone calls in many other settings.

\section{The digital veldt}

As we rely more and more on computers, mobile phones, television and other electronic media for information, consumption, and human interaction, fewer of our activities and smaller parts of our identities are tied to, or shaped by, specific locales or fixed roles. As we face an abundance of easily located information in cyberspace, we are more likely to abandon efforts to gather all we might want and store it in our homes and businesses. Instead, we tend to "store" many items where we found them ("bookmarking" the sites, perhaps), just as nomads leave herds of game and clusters of berry bushes in their natural habitats to be accessed when needed.

When media theorist Marshall McLuhan declared that, with electronic media, we all live in a "global village,"4 he might actually not have reached back far enough for an appropriate analogy. Rather than moving back to a village with relatively set roles and a fixed location, we are, instead, more like global nomads. We return in some ways to the earliest form of human organization, as we spiral forward as hunters and gatherers in a digital veldt. Our migration to this new cultural landscape, however, has been masked by the lack of dramatic changes in the appearance of the houses, offices, neighborhoods, cities, and countries we inhabit.

The digital veldt is unique in human history. Unlike our ancient counterparts, we, as global nomads, are able to violate the rules of physical movement and physical limits. Electronic technologies have been speeding up the crossing of traditional boundaries, by extending our reach across old divisions and borders. Physical barriers - such as mountains, walls, and bar- 
bed wire-have diminished in significance. Physical passageways-such as hallways, rivers, and roads-are no longer the sole channels through which to "travel," "meet," or trade.

Electronic information seeps through walls and leaps across vast distances. While we still often think of electronic media as simply connecting one place to another more quickly, our forms of communication have been subtly but significantly altering the environments we live in, transforming them into new social places in which we are becoming new kinds of people.

A key feature of the electronic era is that most physical, social, cultural, political, and economic boundaries have become more porous, sometimes to the point of functionally disappearing. This seemingly simple proposition has far-reaching significance and implications. The relatively segregated systems that once defined distinct roles, nations, industries, products, services, and channels of communication have been leaking into each other. While the key change is literally happening "at the margins" of all social systems, the change is not simply something happening "out there." As the margins change, the contents of all forms of human organization change. As a result, we are experiencing a dramatic shift in our senses of locale, identity, time, values, ethics, etiquette, and culture.

The increasing functional permeability of boundaries-combined with the continued physical existence of most of those same boundaries-explains the contradictory feelings we have in the early $21^{\text {st }}$ century: Many things still seem the same, and yet everything is somehow changed.

In our electronic landscape, we have thinner distinctions:

- between here and there

- between now and then (and yet to be)

- between public and private

- between male and female spheres

- between child and adult realms of experience

- between leaders and average citizens
- between office and home

- between work and leisure

- between businesses and customers

- between users and producers

- between news and entertainment

- between one field or discipline and another

- between different media genres

- between simulated and real

- between copies and originals

- between direct and indirect experience

- between biology and technology

- between marginal and mainstream

\section{Fusion and fragmentation}

As boundaries become more porous, more permeable, more transparent, we are not experiencing simple homogenization. We are experiencing both new forms of fusion and new forms of disintegration. There are greater similarities across systems that used to be very different and more variations within systems that used to be relatively homogeneous. The world is coming together-and falling apart-in new ways. The changes in the nature of virtually all boundaries underlie what is commonly called "globalization" and what is often described as "post-modernism." The new forms of fusion and disintegration that emerge from such boundary changes lie at the heart of both the excitement and dis-ease over "multiculturalism."

On the macro-level, the world is becoming more homogeneous. Our leaders try to act more like the person next door, even as our real neighbors want to have more of a say in local, national, and international affairs - and, for that matter, in the affairs of presidents. We also see more adultlike children and more childlike adults. And we see more career-oriented women and more family-oriented men. We see more capitalistic Russians, and more communal Americans. People work more while at home and on vacation. It seems unprofessional to be out of touch, even while on the beach. And 
workers play more at the office via electronic games, e-mail, instant messaging, web surfing, and so forth.

Yet along with macro-level blurring, comes micro-level fragmentation. On the micro-level, individuals experience more choice, more variety, and more idiosyncrasy. Just as there is now greater sharing of behaviors among people of different ages and different sexes and different levels of authority, there is also greater variation in the behaviors of people of the same age, same sex, and same level of authority.

Unlike modern literate society, which highlights differences between groups and the interchangeability of people within social categories, the current, postmodern trend is toward integration of members of all groups into a relatively common sphere of experiential options. This is accompanied by a new recognition of the special needs and idiosyncrasies of individuals. While men and women in general now share many roles, individual women are less like each other than they were in the past. The same is true of the greater variety in male roles and child roles. Children behave more like adults, but individual 14-year-olds are less like each other than they once were.

Similar changes are occurring for different locations. Different cities, for example, are becoming more like each other, just as there is more diversity in behavior, activity, and perspectives within given localities. We now live in what I have called "glocalities," places that are unique in many old and new ways, and yet are also influenced by global trends and global consciousness. ${ }^{5}$

In short, the combination of macro integration and micro segregation has led to a dizzying array of significant changes in most electronic societies around the world. ${ }^{6}$ These include:

- a blurring of the lines between different tasks and activities

- a dramatic change in traditional role-systems for people of different ages, genders, groups, and status, with new forms of blurring across old categories and splintering within them

- a change in the experience and functions of local communities

- a change in the identity of products and industries

- the waning of clear geographical concentration of high-tech innovation and expertise

- the decline of national sovereignty as governmental control over informational borders diminishes

- the rise of pan-cultural styles of behavior and dress

- the collapse of action and reaction into coconstructed realities over great distances

- the shift from unidirectional to bi-directional and multidirectional communication

- the flattening of hierarchies and the decline in the significance of many "middlemen"- agents, brokers, mid-level managers - the growing significance of peer (horizontal) feedback, as consumers turn to other consumers' ratings of products, services, and companies

- changing moral boundaries

- the compression of time periods into each other

- new social responsibilities that emerge from new technological possibilities

- the increasing importance of non-governmental organizations (NGO's), and

- a decline in the credibility of mainstream sources of news among those with easy access to alternative news and information.

\section{New promises, new problems}

Global nomadism creates many new possibilities and many new challenges for "a people who mean to be their own governors" (as James Madison, one of America's founding fathers, described a democracy). Not having to be in a particular location to have "experiences" and "interactions" is personally liberating in many ways. Yet such dis-placements also undermine many of the traditional forums for local collective political action. Indeed, the focus on indivi- 
dual, wireless, and group-less interaction is a better match for a culture of consumption than for a culture of citizen sovereignty.

Digital interactions create new means for non-geographic "groups" to act together for economic, social, and/or political purposes. In recent years, electronic media have been used to organize hundreds of thousands of people via petitions, protests, and other political actions in opposition to the global policies of the World Trade Organization (WTO), the World Bank, and the International Monetary Fund (IMF). Worldwide digital coordination led to the largest protests in history on February 15, 2003, as millions of people gathered in the streets of cities around the world in opposition to the U.S.'s planned invasion of Iraq. Even though only a minority of the people who have access to the latest technologies (themselves a small minority of the world's population) have thus far employed them in this manner - with as yet limited influence on government and corporate actions - the potential impact remains great.

For many people, however, the technical possibility of connecting electronically to virtually everyplace as if it were local space may increase the danger of losing the ability to grasp the overview, to see geographical and historical context, to perceive overall patterns. Ironically, the increased potential to access, juxtapose, compare and contrast, and construct alternative narratives is often paired with the reduction in the psychological inclination to engage in such time-consuming analysis. Paradoxically, the more our new technologies allow us to accomplish in an instant, the more we seem to run out of time.

Relying on this paradox, political leaders have discovered that if they can shape the content of the surface information (such as newspaper headlines and front-page stories and the top stories on mainstream television and radio programs and news websites), they can sway the majority of the population-even when contradictory information is easily available to anyone who has the time and inclination to take advantage of computer search technology or alternative news media. In a dramatic recent example, public opinion polls suggested that a majority of the American public accepted the widely reported claims by U.S. government officials about Iraq's nuclear weapons program, its extensive stockpiles of biological and chemical weapons, and its ties to Al-Qaida and the September 11, 2001 attacks on the World Trade Center and Pentagon. These beliefs developed and solidified with the assistance of a mostly compliant mainstream news media in spite of the fact that careful attention - even to the mainstream news (and certainly to alternative media) well before the U.S. invasion of Iraq - would have revealed that each of these claims was highly questionable. $^{7}$ There were good arguments to be made for action against the brutal Iraqi regime, but the most widely circulated and believed claims were apparently false.

The future for us, as global nomads, rests in large measure on how well we balance the ease with which placeless wireless communication creates lone grazers of the digital landscape with the collective need to protect the integrity of the political, economic, social, and environmental characteristics of the world we live in and hope to pass down to our children and their children. We must be thoughtful and vigilant. We cannot automatically assume that the dramatic enhancement of the technical capabilities of our media, with easy access to an increasing amount of information and electronic interactions, will give us the type of control over our destinies that we might desire. As we roam the digital veldt, we must reach beyond the most visible nuggets of information. We must guide the use of our technologies so that their powerful democratizing potentials are realized. Without such vigilance, we may share the fate of our earliest predecessors - the pre-technological nomads - whose local sense of freedom and egalitarian interaction masked the larger forces that threatened the ecosystems that sustained them ${ }^{8}$. 


\section{Notes}

* C2003 Joshua Meyrowitz. All rights reserved.\{3900/Global Nomads H1 JM 5-5-04 4A; 14/05/04 printout\}

1 Although hunting and gathering societies have differed in form over time and in different locations, a close reading of the anthropological literature suggests some general ways in which such nomadic societies have differed from other forms of social organization. For the purpose of analyzing broad contrasts in this brief essay, I discuss hunters and gatherers, as well as other societal forms, as Weberian "ideal types." For relevant detailed studies, see Patricia Draper, "Kung Women: Contrasts in Sexual Egalitarianism in Foraging and Sedentary Contexts," in Rayna R. Reiter (ed.), Toward an Anthropology of Women, New York: Monthly Review Press, 1975, pp. 77-109; Ernestine Friedl, Women and Men: An Anthropologist's View, New York: Rinehart \& Winston, 1975; Jane C. Goodale, Tiwi Wives: A Study of the Women of Melville Island, North Australia, Seattle: University of Washington Press, 1971; Lorna Marshall, The !Kung of Nyae Nyae, Cambridge, MA: Harvard University Press, 1976; Colin M. Turnbull, The Forest People, New York: Simon \& Schuster, 1961; and Charlotte G. O'Kelly, Women and Men in Society, New York: Van Nostrand, 1980. The relevance of hunting and gathering societies to changes in male and female roles in our own time was pointed out to me by Candice J. Leonard, who discusses this idea in her unpublished paper, "Sexual Equality in the Post-Industrial Society," University of New Hampshire, 1983.

2 Friedl, op. cit., suggests that there are four major forms of division of labor among hunters and gatherers, and O'Kelly, op. cit. adds a fifth: 1) both men and women gather, men hunt; 2) communal hunting and gathering by both men and women; 3 ) men hunt, women gather; 4) men hunt, women process the meat and skins; 5) women hunt and gather, men hunt and fish. Friedl notes that the more gender overlapping there is in subsistence tasks, the greater the general gender equality in the society, an observation that is consistent with the theoretical framework presented in this essay.

3 Erving Goffman, The Presentation of Self in Everyday Life, New York: Anchor, 1959, p. 106.

4 Marshall McLuhan, Understanding Media: The Extensions of
Man, Cambridge, MA: MIT Press, 1994 (originally published 1964), p. 34.

5 Joshua Meyrowitz, The Changing Global Landscape, Atlanta: Quest, 1991.

6 For further discussion of these trends, see Joshua Meyrowitz, "Global Permeabilities," in Enrique Rodriguez Larreta, (ed.), Media and Social Perception, Rio de Janeiro: Unesco/ISSC/Educan, 1999, pp. 423-441.

7 See Joshua Meyrowitz, "Web of Lies," In These Times, 1 September 2003, 18-20<www.inthesetimes.com/comments.php?id=318_0_1_0_C $>$.

8 This essay was originally published in Kristóf Nyíri, (Ed.), Mobile Democracy: Essays on Society, Self and Politics, Passagen Verlag, 2003, 91-102. The author wishes to thank Renée $\mathrm{H}$. Carpenter for her very helpful comments and suggestions. 